\title{
Atitudes responsivas e táticas na escrita do gênero cordel
}

\author{
Lúcia de Fátima Santos ${ }^{1}$ \\ Lídia Maria da Silva Santos ${ }^{2}$
}

\begin{abstract}
Resumo: Este artigo resulta de uma pesquisa desenvolvida no âmbito do Programa Institucional de Bolsas de Iniciação à Docência (PIBID), no curso de Letras, da Universidade Federal de Alagoas (UFAL) e tem como objetivo analisar os posicionamentos adotados por alunos do $9^{\circ}$ ano do ensino fundamental diante das orientações das professoras, em atividades de produção do gênero cordel, observando atitudes responsivas e táticas com base nas reflexões de Bakhtin $(1996,1997)$ e De Certeau $(2002,2005)$, respectivamente. Na análise realizada, foram observadas expressões táticas e responsivas nas produções dos alunos, que subverteram, em alguns momentos, essas orientações, mas sem acontecer um distanciamento total da proposta apresentada pelas professoras.
\end{abstract}

Palavras-chave: Gênero Cordel. Atitudes responsivas e táticas. Alunos do ensino fundamental.

\section{Responsive and tactical actions in writing string booklets}

\begin{abstract}
This article is a result of a research conducted under the Initiation to Teaching Scholarship Institutional Program (Programa Institucional de Bolsas de Iniciação à Docência PIBID) of the Modern Languages Course at Federal University of Alagoas (UFAL) and aims at analyzing the procedures adopted by 9th grade elementary school students after the guidance of their teachers for the production of some string booklets, observing their responsive and tactical actions, based on the reflections of Bakhtin (1996, 2003) and De Certeau (2002, 2005), respectively. In the analysis, students' tactical and responsive expressions while producing the booklets were observed. At some moments, the students subverted these guidelines but this happened without a total gap from the initial proposal given by the teachers.
\end{abstract}

Keywords: String booklets. Responsive and tactical action. Elementary students.

\section{Introdução}

A apropriação da escrita e da leitura pelos alunos de modo que apresentem suas idéias com compreensão continua sendo um trabalho bastante desafiador para professores

\footnotetext{
${ }^{1}$ Doutora em Linguística, professora da Faculdade de Letras da Universidade Federal de Alagoas. E-mail: luciadefatima.letras@gmail.com.

${ }^{2}$ Licenciada em Letras pela Faculdade de Letras da Universidade Federal de Alagoas. E-mail: lidialmss@hotmail.com.
} 
em todas as instâncias de ensino e aprendizagem (desde os anos iniciais da educação básica à universidade), porque, entre vários fatores de adversidades que trazem implicações para essa situação, o número expressivo de alunos nas turmas, por exemplo, inviabiliza o acompanhamento criterioso do processo de aprendizagem de cada aluno, conforme já apontado por Santos (2007). Assim, apesar da diversidade de publicações que discute essa questão e do movimento de redirecionamentos no ensino de língua portuguesa que foi desencadeado a partir dos anos oitenta, o cotidiano das salas de aula evidencia que ainda há muitos alunos que chegam ao final do ensino fundamental sem um domínio de escrita e de leitura correspondente a esse nível de escolaridade, tal como constatamos nas ações concretizadas pelo grupo de Letras/Capes/Ufal que integra o subprojeto do Pibid (Programa Institucional de Bolsas de Iniciação à Docência), num trabalho processual em desenvolvimento em escolas públicas de Maceió desde 2010. As experiências diárias com alunos e professores nos permitem ratificar cada vez mais a idéia de que as alternativas para mudanças no ensino e aprendizagem precisam ser construídas a partir da realidade de dentro da sala de aula, sendo construídas com a participação efetiva dos professores na condição também de pesquisadores.

Neste artigo, que é parte de reflexões de uma pesquisa ${ }^{3}$ desenvolvida no âmbito do Pibid/Letras/Capes/Ufal, temos como objetivo analisar os posicionamentos adotados por alunos do $9^{\circ}$ ano do Ensino Fundamental diante das orientações das professoras (também pesquisadoras) em atividades de leitura e produção, realizadas em oficinas sobre o gênero cordel, observando atitudes responsivas e táticas expressas pelos alunos em seus textos. Nesse sentido, a análise será direcionada pelas seguintes questões: a) Como os alunos apresentam atitudes responsivas e táticas em suas produções? b) Como as condições de produção interferem no processo de produção dos alunos? c) Como os alunos se apropriam das características do gênero cordel em seus textos, atendendo (ou não) às orientações das $\operatorname{professoras}^{4}$ ?

\footnotetext{
${ }^{3}$ A pesquisa resultou no Trabalho de Conclusão de Curso de Lídia Santos, intitulado "O gênero cordel em oficinas do Pibid: a posição dos alunos às orientações das professoras", defendido na Faculdade de Letras, na Universidade Federal de Alagoas, em 2010.

${ }^{4} \mathrm{O}$ uso do plural se justifica porque o trabalho era realizado de forma cooperativa pelas professoras da formação inicial (bolsistas de iniciação à docência) e pelas professoras da formação continuada (coordenadora e supervisora: essa é a denominação adotada pela Capes).
} 
Na primeira parte do artigo, mencionaremos as abordagens teóricas que orientaram a pesquisa (considerações sobre responsividade e tática, gêneros discursivos e sobre o gênero cordel); em seguida, faremos uma breve contextualização dos dados analisados e, por fim, apresentaremos a análise propriamente dita.

\section{Responsividade e tática}

Opondo-se à visão monológica e passiva de construção do conhecimento defendida pelas ciências exatas, Bakhtin (1997, p. 291) postula para as ciências humanas um tipo de compreensão denominado de compreensão responsiva ativa: que corresponde à "fase inicial e preparatória para uma resposta (seja qual for a forma de sua realização)." Toda compreensão de um enunciado concreto pressupõe uma atitude responsiva ativa, é "prenhe de resposta e, de uma forma ou de outra, forçosamente a produz: o ouvinte tornase locutor” (BAKHTIN, 1997, p. 290). Ainda, segundo esse autor, poderá acontecer de a resposta não ser emitida imediatamente, correspondendo, por um certo tempo, compreensão responsiva de ação retardada, porém, em algum momento, o que foi ouvido e compreendido de modo ativo será respondido, de algum modo, pelo ouvinte.

A compreensão responsiva ativa ocorre em relações intersubjetivas no fluxo ininterrupto da comunicação verbal. Na concretização dessas relações, Bakhtin (1997) elege o diálogo como a forma clássica da comunicação verbal, que pode acontecer de dois modos: em situações sociais imediatas (nas interações do cotidiano) ou amplas (nas esferas da comunicação cultural) de interação verbal. Em qualquer uma das situações, as relações dialógicas se definem como relações de sentido, “cujos elementos só podem ser enunciados completos (ou considerados completos, ou ainda potencialmente completos), por trás das quais está um sujeito real ou potencial, o autor do determinado enunciado" (BAKHTIN, 1997, p. 353).

Nessas relações dialógicas, locutor e interlocutor mantêm uma relação de 
alternância de lugares e de posicionamentos: "o locutor termina seu enunciado para passar a palavra ao outro ou para dar lugar à compreensão responsiva do outro" (1997, p. 294). Assim, mesmo "uma breve e fragmentária réplica" pressupõe uma posição responsiva, onde são firmados diferentes tipos de relação, seja de pergunta-resposta, concordânciadiscordância, afirmação-consentimento, oferecimento-aceitação, entre outros. Bakhtin (1997, p. 291) aprofunda esse caráter de dialogicidade da linguagem a ponto de reconhecer o próprio locutor como, de certo modo, um respondente, uma vez que diferentes discursos - dele mesmo em momentos anteriores - permeiam o seu dizer. Entretanto, é importante enfatizar que não se trata de uma relação monológica, tal como prevista pelas orientações do objetivismo abstrato e do subjetivismo idealista. Em Bakhtin, mesmo as reflexões do sujeito consigo mesmo são relações dialógicas, ou seja, fundadas em relações intrinsecamente vinculadas a outros enunciados na cadeia da comunicação verbal, resultam, portanto, de interações sociais. Assim “todo monólogo é réplica de um grande diálogo (da comunicação verbal) dentro de uma dada esfera” (BAKHTIN,1997, p. 345). Nossos enunciados estão repletos de palavras dos outros.

Ainda no âmbito das relações interativas, De Certeau (2002, p. 96-97) concebe o ato de falar como "um uso da língua e uma operação sobre ela", na qual o enunciado supõe quatro etapas relativas ao seu uso: realização, apropriação por parte do falante, inserção em uma rede relacional (um enunciado é dirigido a alguém), instauração situação (contexto de uso). É a partir dessa discussão acerca do enunciado que o autor introduz a discussão sobre o uso que se faz dos produtos na sociedade (nesse caso, o enunciado, mas podendo se referir também a diferentes elementos presentes na sociedade, como por exemplo, a religião e a escrita). De Certeau (2002) evidencia que, por mais que a mídia (dentre vários outras instâncias de poder) busque uma unificação do que é lançado ao público (ou melhor, aos consumidores), os modos de "consumir" o que é oferecido é que modifica o uso do objeto vendido.

De Certeau (2002, p. 99) denomina de estratégia a ação de criar essas determinações visando a uma posição de comportamento homogeneizante dos 
consumidores. Segundo ele, a estratégia é "o cálculo (ou a manipulação) das relações de forças" que "postula um lugar suscetível a algo próprio". E acrescenta afirmando que toda ação estratégica tem como finalidade "distinguir de um "ambiente" um "próprio", isto é, o lugar do poder e do querer próprios".

O referido autor (2002, p. 100) afirma ainda que "a tática é determinada pela ausência de um próprio". "A tática não tem por lugar senão o do outro, por isso nenhuma delimitação externa lhe possibilita condições de autonomia. Diante disso, segundo o autor, a tática consiste na arte do fraco materializada por meio de ações calculadas que surgem da ausência de um próprio. Esse movimento acontece "dentro do campo de visão do inimigo", não acumula vitórias e acontece, muitas vezes, em um curto espaço de tempo, no instante em que as conjunturas dominantes apresentam uma faísca de fragilidade (DE

CERTEAU, 2002). O autor diferencia essas duas ações atribuindo à estratégia o "estabelecimento de um lugar"; e à tática, a "utilização do tempo", o que torna mais visível o fato de a estratégia acumular seus ganhos, e as táticas não conservá-los. Ainda, de acordo com De Certeau (2002), as atitudes táticas surgem da escolha de um modo de usar um determinado produto imposto pela classe dominante. É por meio desse uso que se subverte o que já está predeterminado pelos produtores.

Assim, atitudes responsivas e táticas podem acontecer em qualquer relação de interação, Nas práticas pedagógicas, como veremos na análise, por um lado, o professor elabora atividades determinando, em geral, o modo como o aluno a realizará e, por outro, o aluno a realiza, podendo agir como sujeito responsivo e tático quando busca uma forma além da já esperada, demonstrando outro uso para o produto (atividade) apresentado pelo professor e inserindo marcas de sua subjetividade, como poderá acontecer na produção de diferentes gêneros discursivos.

\section{Gêneros do discurso: algumas considerações}

Segundo Bakhtin (2003), a língua é efetivada por meio de enunciados, e cada esfera de uso da língua produz "tipos relativamente estáveis de enunciados", denominados como gêneros do discurso (BAKHTIN, 2003, p. 262). Os gêneros são produzidos de acordo 
com as condições de produção, ou seja, são determinados pelas condições socioculturais e históricas nas quais eles surgem, pela finalidade que eles objetivam e pelas especificidades do campo comunicativo do qual eles fazem parte. Sendo assim, são elaborados para estabilizar, mesmo provisoriamente, os enunciados e promover interações entre os interlocutores, materializando, desse modo, as práticas sociais. Ainda segundo esse autor (2003, p.261), os gêneros do discurso são compostos por três elementos fundamentais: conteúdo temático, que define conteúdos ideologicamente conformados dizíveis através de um gênero; estilo, que pode tanto dizer respeito à individualidade de quem o produz, como também ao modo como a linguagem é utilizada por um grupo/comunidade ou esfera da atividade humana na produção de gêneros por eles utilizados; construção composicional, que define os aspectos estruturais necessários a sua produção.

Apesar de os gêneros serem compostos por esses três elementos, Marcuschi (2005, p. 19) atenta para o fato de não serem "instrumentos estanques e enrijecedores da ação criativa", pelo contrário, eles se caracterizam por serem "altamente maleáveis, dinâmicos e plásticos”, ou seja, são passíveis de alterações, reformulações e, até mesmo, incorporações a outros gêneros, resultando em novos tipos de enunciados. No entanto, é importante ressaltar que essas mudanças surgem em virtude das práticas discursivas realizadas pelos sujeitos, de acordo com o contexto sociocultural e histórico no qual eles se inserem. Marcuschi (2005, p. 23) estabelece ainda uma distinção fundamental entre gêneros e tipos de texto, na qual a expressão "tipos de texto" faz referência à "construção teórica definida pela natureza linguística de sua composição" (narração, argumentação, exposição, descrição, injunção); e o termo "gêneros" faz referência às ações sociais dos sujeitos para agirem sobre e no mundo por meio da linguagem.

A inserção dos gêneros na escola é o foco de discussão de Schneuwly e Dolz (2010). Esses autores abordam desde a justificativa para se trabalhar com os gêneros até propostas de sequências didáticas a serem realizadas em sala de aula. Para eles, há uma falta de correspondência entre as propostas de atividades com os gêneros em sala de aula e como, de fato, eles são tratados nas escolas. Diante dessa discussão, eles apresentam três abordagens adotadas pelas escolas quando se trata dos gêneros do discurso. 
A primeira abordagem tem relação com o tratamento dos gêneros como objetos de ensino-aprendizagem. Conforme Schneuwly e Dolz (2010, p.65), “o aluno encontrase, necessariamente, num espaço 'como se', em que o gênero funda uma prática de linguagem que é, necessariamente, em parte, fictícia, uma vez que é instaurada com fins de aprendizagem". Esse trabalho desenvolvido pela escola tem como consequência, segundo os autores, a naturalização dos gêneros por eles serem trabalhados tendo como objetivo uma “dominação”, ou seja, a memorização de sua estrutura e características, sem que sejam relacionados às práticas discursivas, efetivamente, realizadas por alunos e professores, isto é, sem uma ligação entre o uso da linguagem e a situação de interação. Desse modo, os gêneros são usados meramente como instrumentos de desenvolvimento e avaliação das capacidades de escrita dos alunos.

A segunda abordagem apresentada por Schneuwly e Dolz (2010, p. 65) trata a escola como um lugar de comunicação e concebe as situações escolares como ocasiões de produção e recepção de textos, relacionando-se com a proposta comunicativa de linguagem ${ }^{5}$. Dentro dessa abordagem de ensino de produção de textos, os autores destacam os gêneros seminários, textos livres, correspondências escolares (informativos), jornal de classe, romances coletivos e poemas individuais, restringindo o universo dos gêneros apenas à esfera escolar sem que se faça menção a outros gêneros que circulam fora da escola, distanciando os alunos das práticas realizadas em sociedade e impedindo, assim, a formação dos alunos enquanto sujeitos responsivos e táticos, tal como defende Santos (2007).

Já a terceira abordagem, de acordo com Schneuwly e Dolz (2010, p. 67), busca uma "negação da escola enquanto lugar particular de comunicação" no sentido de não considerá-la produtora de suas próprias práticas de linguagem. Propõe-se, então, que os gêneros entrem na escola tal como circulam na sociedade, desconsiderando-a enquanto lugar de práticas específicas. Ao contrário da acepção anterior, que propunha a escola enquanto instituição isolada da sociedade, esta defende uma escola sem caracterização

\footnotetext{
${ }^{5}$ Conforme Bakhtin (2003) apresenta, nessa concepção de linguagem “o enunciado satisfaz ao seu objeto (isto é, o conteúdo do pensamento enunciado) e ao próprio enunciador". Havendo outro participante no processo de comunicação, assumiria o papel de ouvinte do enunciado proferido.
} 
própria, desconsidera a escola enquanto lugar particular de ensino-aprendizagem, sendo essa apenas uma extensão da sociedade.

Schneuwly e Dolz (2010, p.68) trazem uma proposta de revisão desses três posicionamentos por eles apresentados e ressaltam a importância de se considerar dois pontos de grande relevância no trabalho com os gêneros quando se objetiva o uso adequado e a apropriação dos mais diferentes usos da linguagem por parte dos alunos. Em primeiro lugar, é necessário haver uma definição precisa dos objetivos de aprendizagem a ser atendidos por meio do trabalho com o gênero escolhido; e em seguida, eles ressaltam a necessidade de criação de situações comunicativas que se aproximem ao máximo de situações reais, mas sem descartar que os objetivos vão além dos objetivos pretendidos por determinado gênero, visto que também se relacionam com os objetivos ligados ao desenvolvimento da aprendizagem do aluno nas práticas de uso da linguagem.

Nessa quarta abordagem, os gêneros passam a ser vistos em uma perspectiva de letramento, ou seja, tornam-se meios que possibilitam aos alunos uma participação responsiva e tática, como prevêem Bakhtin $(1996,1997)$ e De Certeau $(2002,2005)$ em diversas práticas dialógicas dos grupos sociais de que participam.

\section{O gênero cordel}

As origens do cordel nordestino têm relação com o hábito milenar de contar histórias e remonta à Idade Média, conforme apresentam Galvão (2000, p. 23) e Evaristo (2000, p. 119). Essas histórias, inicialmente, eram contadas oralmente por camponeses e marinheiros (EVARISTO, 2000, p. 119), passaram a ser produzidas por artesãos, os quais, tempos depois, por meio da tipografia, passaram a imprimi-las, resultando, desse modo, na transposição da modalidade oral para a escrita (EVARISTO, 2000, p. 120).

A chegada do cordel ao Brasil é associada ao período de colonização do país e tem como justificativa o fato de os portugueses terem trazido cordéis consigo quando chegaram ao País. Vários países europeus apresentam gêneros literários que possuem 
características também presentes no cordel. Em Portugal, esse gênero é conhecido como literatura de cordel ou folhas soltas; na França, é conhecido como colportage (que significa mascate); na Inglaterra, chapbook ou balada; e na Espanha, pliego suelto (MEYER, 1980 apud GALVÃO, 2000).

No entanto, segundo Abreu (1993), o cordel brasileiro não é o mesmo de Portugal. Conforme essa autora (1993, p. 128), “os textos portugueses encontraram no Nordeste uma outra literatura, em processo de definição". Essa autora afirma ainda que as criações poéticas nordestinas fazem parte de uma tradição anterior à publicação de cordéis e que estes passaram a ter sua forma definida no espaço de produção poética já existente. Abreu (1993, p. 4), questiona o uso da nomenclatura "literatura de cordel", visto que, conforme apresentado por Galvão (2000, p. 21), esse gênero é conhecido assim apenas pela academia, sendo nomeado por diversas ${ }^{6}$ outras formas $^{7}$.

Apesar de essa literatura ter forte ligação com o Nordeste brasileiro, Abreu (1993, p. 117) atenta para o fato de haver uma produção também no Rio de Janeiro e em São Paulo, no entanto essa produção é anônima, tanto que se conhece apenas um autor. No Sudeste, os cordéis tiveram sua decadência por volta do ano de 1888, segundo Silvio Romero (apud ABREU, 1993, p.118); já no Nordeste, a primeira publicação de que se tem conhecimento é datada de 1893. No entanto, conforme Evaristo (2000, p. 121), a partir da década de 1950 alguns estados do Sudeste, como, por exemplo, São Paulo e Rio de Janeiro, começarem também apresentar produtores de cordéis advindos dos processos migratórios. De acordo com o estudo de Resende (2007), essa migração do cordel aconteceu devido às condições melhores de venda nos grandes centros.

Retomando as características inerentes aos gêneros do discurso apresentadas por Bakhtin (2003, p. 261), o cordel nordestino apresenta diversos conteúdos temáticos. Estes

\footnotetext{
${ }^{6}$ Galvão (2000, p. 21) apresenta os termos: "folheto", "livrinho de feira", "livro de histórias matutas", "romance", "folhinhas", "livrinhos", "livrinhos ou livrozinhos velhos", "livro de história antiga", dentre outras.

${ }^{7}$ Apesar de Abreu (1993, p. 5) apresentar uma distinção que nomeia como literatura de folhetos a produção brasileira, e como literatura de cordel a produção lusitana, será adotado, neste trabalho, a nomenclatura literatura de cordel, tendo em vista que esse nome é o que tem maior circulação nos trabalhos acadêmicos, na mídia e é adotado pela Academia Brasileira de Literatura de Cordel (ABLC) ${ }^{7}$, facilitando a correspondência entre o nome e o objeto aqui tratado.
} 
são classificados de diferentes formas por vários autores. Um trabalho que apresenta várias dessas classificações é a dissertação de Carvalho (2010), na qual a autora apresenta classificações produzidas por Alves Sobrinho (2003), Pinheiro e Lúcio (2001) e Suassuna (apud SALLES, 1985). Conforme a autora apresenta, várias das "classificações temáticas" envolvem, também, classificações que dizem respeito à forma, a exemplo disso, as pelejas, os ABCs, debates, discussões, encontros e romances.

Já a construção composicional dos cordéis varia em dois aspectos: de acordo com o número de páginas e o esquema das rimas. Segundo Carvalho (2010, p. 51, os cordéis podem ser compostos por sextilhas e classificados como folhetos com 8,12 e 16 páginas ou romances com 24, 32, 48 ou 64 páginas; possuem que podem ser compostos por sextilhas (ABCBDB, ou XAXAXA), septilhas (em ABCBDDB) ou décimas (em ABBAACCDDC).

Desde suas origens até os dias atuais, os cordéis vêm passando por diversas mudanças que contribuíram para a resistência desse gênero diante da invenção do jornal, do rádio, da televisão e da internet. Resende (2007, p. 411) apresenta em seu trabalho diversas mudanças sofridas pelo cordel. Segundo a autora, os textos desse gênero tiveram sua extensão reduzida, visto que no período tradicional sua produção era bem marcada pela quantidade de romances (com até 64 páginas) e, atualmente, essa produção tem caracterizado-se pela quantidade de cordéis circunstanciais ${ }^{8}$, contendo no máximo 16 páginas. Ainda segundo Resende (2007, p. 411), também houve mudança dos pontos de venda dos livretos, porque "o cordel migrou das feiras e mercados nordestinos para lojas de artigos turísticos e aeroportos [...] e é vendido por comerciantes, o que elimina o contato direto do cordelista com seu público", resultando na elitização da cultura popular.

Resende (2007, p. 413) apresenta ainda a mudança referente aos autores - que antes eram pouco instruídos, porém, atualmente, possuem um contato maior com a cultura letrada, sem contar com os poetas ditos eruditos, que escrevem não por profissão, mas por

\footnotetext{
${ }^{8}$ Segundo Resende (2007, p.302), o cordel circunstancial é constituído de, no máximo, dezesseis páginas, com estrofes escritas em sextilhas com versos setessilábicos, com padrão de rima ABCBDB.
} 
lazer. Também houve alteração em relação aos temas - com o passar dos anos houve uma escassez de histórias românticas, passa o enfoque para as questões sócio-políticas. Quanto à produção, impressão e circulação - o que antes acontecia de modo artesanal, passou a ser informatizado: há casos de cordéis produzidos por meio de trocas de e-mails; a tipografia passou a dar lugar a impressão em papel $o f f-s e t^{9}$, além da circulação de textos desse gênero pela internet, como por exemplo os sites da ABLC, Casa Rui Barbosa ${ }^{10}$ e o Portal do Cordel $^{10}$.

Desde suas origens, o cordel trazia consigo o papel de letrar as pessoas que tinham um baixo nível ou, até mesmo, nenhum contato com a escolarização. Esse fato é evidenciado por autoras como Galvão (2000) e Resende (2007). Na pesquisa desenvolvida, o gênero em foco foi trabalhado com o objetivo promover a leitura, discussão e produção do cordel como atividade de leitura e valorização da cultura local, sob uma perspectiva de responsividade e tática.

\section{Contextualizando os dados}

Os dados aqui analisados, conforme já anunciamos, foram obtidos através de uma pesquisa desenvolvida em uma turma de $9^{\circ}$ ano do ensino fundamental de uma escola de rede pública de ensino do Estado de Alagoas, no ano de 2010, a partir do trabalho realizado por integrantes do Pibid/Letras/Capes/Ufal: professora-coordenadora, professorasupervisora e bolsistas ${ }^{11}$. Os alunos que integravam essa turma tinham uma idade entre 13 e 17 anos, alguns apresentavam um histórico de repetência em algumas séries. De um modo

\footnotetext{
${ }^{9}$ No entanto, há cordelistas que se recusam a aderir às novas tecnologias, como pode ser visto na entrevista com José Lourenço, no trabalho de Resende (2007, p. 417). 10 Disponível em: $<$ http://www.casaruibarbosa.gov.br/cordel>

${ }^{10}$ Disponível em: <http://www.portaldocordel.com.br/>

${ }^{11}$ No decorrer da análise, as bolsistas (professoras em formação inicial) e a supervisora (professora em formação continuada) serão referenciadas apenas como professoras, porque conduziram o trabalho em conjunto durante as aulas.
} 
geral, todo o grupo era muito assíduo às aulas. Como se tratava de adolescentes, eram muito inquietos, mas participavam bastante das aulas.

A coleta de dados ocorreu em dois momentos distintos, porém inter-relacionados: o primeiro, de observação; o segundo, de intervenção. As bolsistas observaram a turma durante os primeiros quatro meses de investigação, assistindo a todas as aulas de Língua Portuguesa (LP), fazendo anotações das atividades apresentadas pela professora, anotações de campo e diários reflexivos ${ }^{12}$. Esse contato inicial foi necessário para que houvesse conhecimento da turma e de outros aspectos da realidade escolar.

No quinto mês, a escola propôs a realização de um projeto que tinha como objetivo discutir sobre as contribuições da cultura africana para a cultura alagoana. A turma do $9^{\circ}$ ano ficou com a atribuição de pesquisar sobre a relação da culinária africana na culinária alagoana e apresentar os resultados da pesquisa por meio do gênero cordel. Para orientar esse trabalho, os integrantes do Pibid planejaram e ministraram sete oficinas de leitura e produção de textos sobre a temática do projeto em foco.

A primeira oficina objetivava inserir a turma no universo dos cordéis. Para isso as professoras iniciaram o momento com a leitura do cordel "Peleja do aluno preguiçoso com o estudioso" ( $C f$. ANEXO). Após a leitura do texto, elas mediaram uma discussão por meio de questões como: "Já ouviram algo parecido? Onde? Em que situação? Onde podemos encontrar esses livros? Onde eles são vendidos? Alguém sabe como eles são chamados? Por que eles são chamados assim?”. A partir dessas perguntas, os alunos foram construindo, juntamente com as professoras, seus conhecimentos sobre o gênero estudado. Ainda nessa oficina, houve um momento de leitura, no qual vários cordéis foram distribuídos na turma para que os alunos lessem e tecessem comentários sobre o que haviam lido.

Na segunda oficina, a ideia de produção de um cordel sobre culinária foi introduzida, mas ainda não desenvolvida. Para situar a turma diante da temática, realizouse

\footnotetext{
12 Produção escrita a partir das experiências vivenciadas no decorrer das aulas ministradas por professoras e por bolsistas, apresentando os registros dos acontecimentos e propiciando um maior aprofundamento na reflexão sobre a própria prática pedagógica, relacionando-a com as teorias adotadas.
} 
uma dinâmica sobre comidas e houve também um momento de trocas de experiências ${ }^{13}$ entre professoras e alunos sobre culinária. Na terceira oficina, os alunos relataram essas experiências por escrito e produziram acrósticos de seus nomes a partir da denominação de pratos culinários. No final dessa oficina, as professoras pediram que a turma fizesse uma pesquisa em casa sobre culinária e receitas africanas que faziam parte da cultura alagoana.

Na quarta oficina, os acrósticos foram apresentados. Além disso, houve também a socialização da pesquisa sobre culinária e a leitura de cordéis que versavam sobre comida. Após os momentos de socialização e leitura, foi proposto aos alunos que produzissem cordéis sobre a relação entre culinária africana e alagoana. As orientações dadas para a produção dos textos foram as seguintes:

Proposta: Produzam um cordel que fale sobre a presença da culinária africana na sua ou sobre a relação entre a culinária africana e a culinária alagoana/nordestina (podem falar de alguma receita, alguma comida de que vocês gostem muito ou que vocês cozinham). (Fragmento do planejamento das oficinas).

A turma concordou com a proposta e cada grupo ${ }^{14}$ produziu seu texto. Ao todo, foram produzidos quinze textos. Após a produção, os bolsistas fizeram intervenções nos textos dos alunos por meio de bilhetes, e todos os grupos que estavam presentes à aula, na quinta oficina, realizaram a reescrita dos seus textos. $\mathrm{Na}$ sexta oficina, cada grupo apresentou sua produção para a turma.

A sétima e última oficina foi destinada à confecção das capas em xilogravura. $\mathrm{O}$ processo de xilogravura, que consiste na gravação de imagens em placas de madeira com o uso de estiletes e talhadeiras, foi adaptado pela gravação de imagens em pratinhos de

\footnotetext{
${ }^{13}$ Neste momento, os alunos que declaram não ter experiências para contar, compartilharam alguma receita de família com a turma.

${ }^{14}$ Alguns alunos resistiram em realizar a produção em grupo. Por essa razão, algumas produções foram realizadas individualmente.
} 
isopor, para que os alunos não se submetessem ao risco de trabalhar com instrumentos cortantes e perfurantes. Todos os grupos produziram livretos com capa em xilogravura.

No dia da finalização do projeto, os alunos expuseram quinze livretos em um grande varal estendido na quadra da escola, socializando assim a experiência de uma situação real de circulação e leitura do gênero cordel, produzida por eles para toda a comunidade escolar. Esses livretos constituíram o corpus da pesquisa.

Devido à necessidade de delimitações deste artigo, selecionamos duas produções desse corpus que se caracterizam como: 1) a mais representativa do grupo de alunos que cumpriu com as orientações adotadas pelas professoras; 2) a mais representativa do grupo que cumpriu parcialmente as orientações propostas pelas professoras, compreendendo que quanto mais os alunos subvertiam a proposta da atividade, mais apresentavam indícios de atitudes responsivas e táticas.

\section{A análise dos dados}

$\mathrm{Na}$ análise dos dados, observamos que, das quinze produções elaboradas na oficina, nove correspondem totalmente à proposta de produção. Essas nove produções apresentam marcas do gênero receita em sua constituição, muitas vezes trazendo transcrições do modo de preparo de alguns pratos. Isso se deve ao fato de uma das orientações dadas pelas professoras ter sido mais aceita pelos alunos, por isso apareceu muito marcadamente na maioria das produções. De modo insistente, as professoras lembraram as discussões sobre receita, talvez pelo receio de os alunos se distanciarem do tema do projeto pedagógico: pesquisar sobre a relação da culinária africana na culinária alagoana. É interessante considerar que, mesmo ocupando o lugar de professoras que faziam autorreflexões sobre o seu fazer pedagógico e reconheciam a necessidade de os alunos terem uma autonomia relativa, elas repetiram insistentemente a proposta para que os alunos as cumprisse integralmente. Ou seja, as professoras estavam subordinadas às determinações da escola e, desse modo, orientavam os alunos para que também agissem assim. Porém, todos os alunos conseguiram alçar outros voos e captar possibilidades de ganhos e conquistas de novos espaços (DE CERTEAU, 2002), mesmo ainda exíguos. 
Enquanto o primeiro bloco de produções se aproxima bastante das instruções dadas pelas professoras, inclusive fazendo referência a aspectos do gênero receita; o segundo bloco, composto por cinco produções, apresenta textos que apontam para um distanciamento das orientações. Estas produções se diferenciam daquelas por não corresponderem às características do gênero receita, conforme exporemos a seguir.

\subsection{Produções que mais corresponderam à proposta das professoras}

As produções do primeiro grupo correspondem integralmente à proposta da atividade: os alunos mencionam a relação entre a culinária africana e a alagoana/nordestina, inclusive fazem referência às características do gênero receita. No total, como já foi dito, nove produções se agrupam nessa classificação (Acarajé15, Quibebe africano, O saboroso vatapá, O cuscuz nordestino, Mugunzá, Cocada, Pédemoleque, A feijoada), porém o texto mais representativo intitula-se "A feijoada ${ }^{16 "}$.

A comida africana Ela é muito especial Todo mundo gosta Ela é sensacional

A feijoada nordestina Ela é especial foi feita lá na África e tornou-se a febre nacional

Você quer saber como se faz a feijoada africana? ela é feita com amor, com carinho, ela é baiana

depois de preparado pegue um prato e bote arroz coma enquanto está quentinho e não deixe pra depois

\footnotetext{
${ }^{15}$ Dos nove textos, dois são intitulados "Acarajé".

${ }^{16}$ A feijoada tem origem controversa. As versões mais conhecidas são as que afirmam ser um prato inventado nas senzalas por escravos africanos e as que indicam ter uma origem europeia. Durante o Projeto, considerou-se a versão de origem afro-brasileira por ser a mais veiculada, como aborda Elias (2007, p. 33).
} 
Nesse texto produzido por três alunas, é perceptível a preocupação do grupo quanto à regularidade das rimas, que segue o esquema XAXA em todas as quatro estrofes, o que indica uma aproximação com o gênero cordel. Ainda que não seja um esquema de rimas próprio do gênero em questão, que adota o esquema XAXAXA, vale enfatizar a tentativa dos alunos de elaborar um esquema bastante aproximado. Embora não produzam sextilhas, eles propõem as rimas alternadas em quartetos. De um modo geral, verificamos essa tentativa de construir rimas seguindo esse esquema na maior parte dos textos, porém houve dificuldade na elaboração de sextilhas. A rima em sextilha no esquema XAXAXA, tal como acontece nos cordéis de autores consagrados, somente se observa em uma estrofe do texto "Pé-de-moleque":

\footnotetext{
Vou falar de culinária Uma coisa interessante A culinária africana Tem comidas fascinantes Começando por um doce Que gostamos bastante
}

Nesse texto, há rimas em outras estrofes, mas não seguem nenhum dos esquemas previstos na constituição do gênero cordel. Apenas no texto "A feijoada" todas as estrofes são quartetos com rimas no padrão XAXA e, embora não se trate de sextilhas, obedecem à regularidade própria do gênero cordel. Tendo em vista essas considerações acerca das características formais desse gênero, considera-se que o grupo que produziu o texto "A feijoada" compreendeu que o cordel possui uma caracterização específica, desde sua divisão em versos e estrofes até a sonoridade presente nas rimas e em seus diferentes esquemas.

Outro aspecto que vale mencionar no texto "A feijoada" é que, como o título sugere, há uma adequação à proposta temática do projeto, visto que esse prato faz parte das culinárias africana e da nordestina, sendo bastante apreciado, conforme indicam os trechos "ela é muito especial" e "todo mundo gosta". Provavelmente, essa generalização justifique-se pelos relatos apresentados pelos alunos nas discussões em sala de aula, 
quando eles explicitaram suas experiências gastronômicas vivenciadas em seu contexto social.

Já na segunda estrofe, o grupo introduz uma nova ideia, especificando a comida que será mencionada em seu texto por meio da relação entre a culinária africana e a nordestina. Essa relação responde às orientações das professoras de LP e dos professores de outras disciplinas que também estavam envolvidos no Projeto África. Assim, nas duas estrofes iniciais, o grupo buscou cumprir com a temática proposta para atividade, que seria a relação entre culinária africana e culinária alagoana/ nordestina. Essa correspondência quase integral à proposta da atividade significa o cumprimento dos alunos às orientações previstas pelas professoras e pela escola. Somente a partir da terceira estrofe os alunos se mostram sujeitos responsivos e encontram táticas para que possam se distanciar do que foi determinado pelas orientações, posicionando-se responsiva e taticamente acerca da proposta da atividade.

Eles iniciam a terceira estrofe com uma chamada para a receita da feijoada ao perguntar ao seu leitor: "Você quer saber como se faz a feijoada africana?" Na resposta apresentada à pergunta, os alunos propõem algo inesperado, ao substituírem os ingredientes comuns (feijão, carnes, especiarias) por elementos como "amor" e "carinho", remetendo ao imaginário de que "comida boa é comida feita com carinho" ou até mesmo com o slogan de um tempero amplamente divulgado na televisão como "O tempero do amor". Essa substituição responsiva e tática foi uma ocorrência verificada apenas na produção desse grupo. As alunas fazem uma reapropriação desses dizeres, veiculados pelo mundo estratégico, e propõem a constituição de sentidos não previstos em uma receita culinária, configurando-se assim como uma atitude responsiva e tática. Porém, logo em seguida, talvez por terem percebido essa subversão, elas voltam a cumprir com as determinações estratégicas e repetem informações previstas em diferentes receitas:

“depois de preparado/ pegue um prato e bote arroz/coma enquanto está quentinho".

É importante salientar também que a relação entre África e Nordeste aparece nessa produção de um modo diferente da orientação da atividade. Isso pode ser compreendido como um indício de responsividade e tática, pois os alunos valorizam a culinária africana no início da produção, mas põem em evidência a culinária nordestina quando sugerem que o amor e o carinho presentes na elaboração da feijoada somente 
acontecem por ser feita na Bahia, embora seja um prato mencionado como herança da culinária africana: "Você quer saber como/ se faz a feijoada africana?/ela é feita com amor,/com carinho, ela é baiana".

Na quarta e última estrofe, os alunos apresentam o modo de servir a feijoada, que indica o acompanhamento mais comum da feijoada ${ }^{17}$ (o arroz) e a temperatura adequada para seu consumo (quente). Essa referência ao modo de servir o prato também é encontrada em outros textos, como na produção intitulada Acarajé ("e tem mais/ pode ser servido pra você/ coloque pimenta, camarão seco e vatapá/ depois de provado pode até gostar"); e no texto O cuscuz nordestino (depois que tudo cozinhar/ é só fritar um ovo para acompanhar"), ambos do primeiro grupo. Nos demais grupos, isso não aconteceu porque eles não escreveram o cordel tomando como referência o gênero receita.

Essa semelhança entre os textos do primeiro grupo indica maior correspondência em relação à proposta da atividade. Por essa razão, foi o grupo que menos expressou responsividade e tática.

\subsection{Produções que corresponderam parcialmente à proposta das professoras}

Os textos classificados como os que corresponderam parcialmente à proposta são aqueles que não se restringiram apenas a apresentar características dos pratos culinários, mas inseriram a culinária como parte integrante da cultura do povo alagoano/nordestino. Além disso, alguns desses textos extrapolaram a proposta da atividade ao trazerem aspectos que não abarcam a cultura afro-brasileira, mas apenas aspectos da cultura alagoana. No total, cinco textos compõem esse segundo grupo. Portanto, trata-se de textos que marcam um distanciamento maior da proposta das professoras ou porque não compreenderam a proposta, ou porque compreenderam e não desejaram cumprir integralmente. De qualquer modo, são textos que não representam integralmente os objetivos expressos pelas professoras no momento de solicitação da atividade. Essa situação nos possibilita afirmar que a concordância dos alunos para realizar a proposta da produção do gênero cordel foi

17 Esse acompanhamento é próprio do consumo da feijoada no Brasil, porém se desconhece o acompanhamento desse prato em outras culinárias. 
realizada de um modo que os alunos tiveram uma certa autonomia para imprimir seus interesses no momentos de construção.

O texto em foco na análise dos textos que corresponderam parcialmente à proposta tem como título $\mathbf{O}$ acarajé, é composto por onze versos divididos em três estrofes (a primeira estrofe possui três versos, a segunda e a terceira estrofes possuem quatro versos). Diferentemente dos outros textos, que foram produzidos em grupo, este resulta de um trabalho individual ${ }^{18}$.

\section{O Acarajé}

O acarajé africano

se misturou com o jeito baiano E,

hoje, é prato típico dos alagoanos

O prato até hoje é admirado

Pelos turistas e os

Que estão acostumados

Eles vem trazendo ingredientes

Que são típicos da nossa gente

E tem gente que ainda não gosta

Nem o cheiro mais suporta

Não sabem o que estão perdendo

É a cultura brasileira se desenvolvendo

Assim como aconteceu com a produção A feijoada, em foco na análise dos textos do primeiro grupo, também houve uma preocupação da aluna quanto às rimas, as quais estão presentes em todo o texto e seguem os esquemas AAA, na primeira estrofe; BBCC, na segunda; e DDEE na terceira. Ainda que a organização das rimas não se aproxime dos esquemas próprios do gênero cordel, verifica-se que a autora compreendeu que a divisão em versos e estrofes e a sonoridade presente nas rimas, que se organizam em diversos esquemas, fazem parte da constituição do gênero. Nesse grupo, apenas um dos textos não

\footnotetext{
${ }^{18}$ A aluna realizou a atividade individualmente porque não participou de outras oficinas nem demonstrou interesse em ingressar em um grupo já formado.
} 
apresentou rimas nem uma divisão em versos, além de não trazer uma discussão mais aprofundada sobre a temática proposta. Esse fato pode ser visto tanto como uma incompreensão dos alunos acerca da proposta da atividade, pelo fato de não ter havido uma definição precisa dos objetivos para a elaboração do gênero escolhido (SCHNEUWLY e DOLZ, 2010) como pode ser uma evidência de expressão de tática e responsividade, numa tentativa dos alunos desviaram-se das estratégias.

Ainda no que se refere aos aspectos formais, ao contrário dos textos que compõem o primeiro grupo, apenas um texto, Comidas africanas, apresenta marcas do esquema de rimas XAXAXA.

Milho verde e pamonha

No mês de junho aqui tem

Milho assado e cozinhado

Mungunzá e xerém

A produção $\mathbf{O}$ acarajé foi selecionada como o texto mais representativo desse grupo porque, além de demonstrar a compreensão dos aspectos formais do cordel, conforme dito anteriormente, apresentou uma discussão em que relaciona as culturas africana e nordestina. A aluna iniciou sua produção fazendo uma recuperação das origens do prato culinário por ela escolhido.

Além de recuperar as origens do prato, a aluna explicitou também que o prato sofreu mudanças ao longo das transições, ou seja, ainda que eles tenham conseguido informações sobre as origens dessa comida, ela atentou para o fato de que as especificidades da cultura de cada lugar (África, Bahia, Alagoas) interferiram na elaboração do acarajé. É relevante ressaltar que, durante as realizações das oficinas, não foi mencionada essa questão das mudanças sofridas pelos pratos durante as adaptações em cada realidade cultural. Mesmo com as discussões específicas sobre as contribuições da culinária africana para a alagoana, essa aluna extrapolou a mera reprodução dos conhecimentos adquiridos nas oficinas e nas pesquisas sobre os pratos, ao associar a pesquisa ao contexto cultural em que ela se insere, respondendo de modo responsivo e tático às orientações das professoras, enquanto os outros quatro textos restringiram a produção a uma apresentação dos pratos. 
$\mathrm{Na}$ segunda estrofe, ela continuou abordando o modo como o acarajé foi incorporado à cultura alagoana. Nessa parte do texto, a aluna atentou para o fato de essa comida ser bem aceita na cultura alagoana e muito procurada por turistas que visitam a capital do Estado. Sendo assim, ela trouxe o tema de sua produção para um contexto conhecido pelos colegas, o que contribuiu para o distanciamento da mera citação da receita. Ao não escrever sua produção de acordo com a caracterização do gênero receita, a aluna enfatiza não somente um prato típico de Alagoas, mas também uma contextualização sócio-histórica e cultural da culinária em questão, reflexão presente apenas nesse texto.

A estrofe final do cordel produzido pela aluna reafirma as ideias do conhecimento que ela apresentou ao longo do texto, ainda que ela indique ter adotado, na segunda estrofe, uma posição positiva em relação ao prato, ela apresenta um segundo ponto de vista, que pode ter sido conhecido a partir de experiências anteriores, ou até mesmo nas discussões que precederam a produção do texto: "E tem gente que ainda não gosta/ Nem o cheiro mais suporta." Porém, mesmo reconhecendo a impossibilidade de algumas pessoas não gostarem de acarajé, ela insiste em defender o prazer de saborear essa iguaria ao afirmar "Não sabem o que estão perdendo.” Nesse verso, a aluna explícita o gosto por esse prato típico, emitindo, desse modo, um juízo de valor positivo. Por fim, no último verso da estrofe, ela afirma que a incorporação do acarajé africano é algo representativo no desenvolvimento da culinária brasileira.

\footnotetext{
E tem gente que ainda não gosta

Nem o cheiro mais suporta

Não sabem o que estão perdendo

É a cultura brasileira se desenvolvendo
}

Sendo assim, percebe-se que, por mais que se espere que o aluno execute a atividade de uma determinada forma, é possível que se encontrem diferentes compreensões acerca de uma mesma orientação da atividade. Essa busca de outros modos de fazer não implica uma fuga da proposta, porém indica que a aluna, a partir de sua compreensão responsivamente ativa, silenciosa ou de efeito retardado, responde por meio de sua 
produção ao que foi proposto para as orientações da atividade. Entretanto, essa resposta pode não corresponder ao que as professoras e a escola desejavam, ou seja, não corresponde a uma estratégia. Diante do lugar próprio instituído pela escola, a aluna jogou e aproveitou a ocasião para "captar no vôo possibilidades de ganho" (DE CERTEAU, 2002, p.47), ou seja, tentou imprimir marcas singulares em meio às determinações homogeneizantes.

\section{CONSIDERAÇÕES FINAIS}

Conforme a análise que realizamos, observamos, em diversos momentos, uma posição dos alunos como sujeitos táticos e responsivos por meio dos posicionamentos adotados diante das orientações das professoras, quando extrapolaram e/ou redimensionaram essas orientações. Mesmo quando os alunos desenvolveram a atividade seguindo as orientações determinadas para a elaboração, eles inseriram elementos no texto e propuseram encaminhamentos diferentes daquelas determinadas pelas professoras, como visto na análise da produção que representou o primeiro grupo. Já na análise do segundo grupo, evidenciou-se a possibilidade de os alunos apresentarem uma configuração diferente da proposta determinada, sem que isso acarretasse um não cumprimento ou uma realização inadequada da atividade. Vale considerar nesse sentido que as professoras, mesmo reconhecendo algumas dessas ações dos alunos nos momentos de orientações particulares em cada grupo, bem como nas intervenções nos textos e durante a socialização dos cordéis, elas respeitaram as vontades dos alunos, não exigiram que reescrevessem os textos seguindo integralmente todas as características do gênero cordel.

É importante enfatizar que essas percepções só foram possíveis devido à transformação da experiência com os alunos em objeto de pesquisa, nos permitindo, desse modo, desvelar aspectos acerca de fatos cotidianos da sala e aula sobre os quais não conseguimos ter uma percepção. Erickson (2001, p. 10-11) nos alerta para essa necessidade de um conhecimento criterioso das cenas das salas de aula, porque, segundo ele, a crença de que já conhecemos as salas de aula "cega-nos para as nuances da particularidade na construção local da interação cotidiana como ambiente de aprendizagem". Por meio desse 
deslocamento do lugar de professoras para o de pesquisadoras, nos foi possível enxergar as reações dos alunos em suas produções e suas implicações para o trabalho desenvolvido durante as aulas. Diante dessas considerações, é relevante mencionar a importância de se refletir sobre os objetivos de realização de atividades de escrita na escola, bem como sobre as diferentes respostas apresentadas pelos alunos em relação à proposta lançada pelas professoras. Assim como também atentarmos para o necessário acompanhamento e coparticipação dos professores nos momentos de realização das atividades, por isso a disponibilidade para o atendimento particular ao aluno ou a um grupo é imprescindível. Nas experiências em foco, isso somente foi possível porque havia três professoras atuando cooperativamente em cada turma que tinha, em média, quarenta e cinco alunos.

Quanto à reflexão sobre o cordel nordestino, os alunos compreenderam sua função social relacionada à tradição de contar histórias, relacionando às histórias e relatos cotidianos, dentre outros aspectos constituintes de seu meio sociocultural. Além disso, houve ainda uma apropriação de seus aspectos formais, visto que os alunos dividiram seus textos em versos e estrofes, além da preocupação em apresentar rimas ao longo das produções. Evidentemente, essa prática de autorreflexão pode ser bastante produtiva nas orientações pedagógicas de um modo geral, embora aqui se faça menção apenas ao escopo desta pesquisa.

Os reflexos da contribuição do trabalho com a produção do gênero cordel para a formação dos alunos foram evidenciados de modo mais amplo no dia da exposição de suas produções para toda a escola, momento em que eles apareceram como cordelistas e puderam interagir com os colegas e professores divertindo-se com a leitura de suas produções. A experiência com a produção a partir dos cordéis reafirma a importância de proporcionar ao aluno a oportunidade de eventos de escrita de diferentes gêneros, para que possam se reconhecer como efetivos produtores e leitores de textos. De modo geral, todos os alunos se apropriaram das características do gênero cordel e produziram um texto em correspondência maior ou menor às condições de produção determinadas pelas professoras, conseguindo, quando possível, furar o cerco das determinações e expressar suas marcas singulares. Para isso, contribuiu decisivamente o olhar reflexivo das 
professoras sobre os encaminhamentos, desenvolvimento e culminância das atividades realizadas.

\section{Referências}

ABREU, Márcia Azevedo de. Cordel português/ folhetos nordestinos: confrontos. Um estudo histórico-comparativo. 1993. xxxf. Tese (Doutorado em Literatura) - Departamento de Teoria Literária do Instituto de Estudos da Linguagem da UNICAMP, Campinas, São Paulo, 1993.

BAKHTIN, Mikhail. Os gêneros do discurso. In: Estética da criação verbal. 2. ed. Traduzido por Maria Ermantina G. G. Pereira. São Paulo: Martins Fontes, 1997. p. 279-326.

BAKHTIN, Mikhail; VOLOCHÍNOV, V.N. A interação verbal. In: Marxismo e Filosofia da Linguagem. 3. ed. Traduzido por Michel Lahud e Yara F. Vieira. São Paulo: Hucitec, 1996. p. 110-127.

CARVALHO, Ana Maria de. Literatura de cordel: entre versos e rimas sotádico e sacânicos. 2010. xxxf.Dissertação (Mestrado em Letras) - Instituto de Letras e comunicação da UFPA, Belém, Pará, 2010.

DE CERTEAU, Michel. A cultura no plural. 4. ed. São Paulo: Papirus, 2005.

DE CERTEAU, Michel. A invenção do cotidiano: artes do fazer. 7. ed. Petrópolis: Vozes, 2002.

DIÉGUES JÚNIOR, Manuel. Literatura de cordel. In: BATISTA, Sebastião Nunes. Antologia da Literatura de Cordel. Natal: Maninbu, 1977.

ELIAS, Rodrigo. Feijoada: breve história de uma instituição comestível. Textos do Brasil, n.13, 2007. Disponível em: <http://dc.itamaraty.gov.br/imagens-e-textos/revista-textosdobrasil/portugues/revista13-mat6.pdf>. Acesso em: 6 dez. 2013. 
ERICKSON, Frederick. Prefácio. In: COX, Maria Inês P. \& ASSIS-PETERSON (Org.). Cenas de sala de aula. São Paulo: Mercado de Letras, 2001, p. 9-17.

EVARISTO, Marcela Cristina. O cordel em sala de aula. In: Gênero do discurso na escola: mito, conto, cordel, discurso político, divulgação científica. São Paulo: Cortez, 2000. p. 119-140.

GALVÃO, Ana Maria de Oliveira. Ler/ouvir folhetos de cordel em Pernambuco. 2000. 537f. Tese (Doutorado em Educação) - Faculdade de Educação da UFMG, Belo Horizonte, Minas Gerais, 2000.

KLEIMAN, Angela. Letramento e suas implicações para o ensino de língua materna. Signo. Santa Cruz do Sul, v. 32, n. 53, p. 1-25, dez. 2007.

KLEIMAN, Angela. Preciso "ensinar" o letramento? Não basta ensinar a ler e escrever? [s.1.]: Cefiel/Unicamp \& MEC, 2005.

MOITA LOPES, Luiz Paulo (Org). Por uma linguística aplicada Indisciplinar. São Paulo: Parábola, 2006.

NEVES, Vanessa Ferraz Almeida. Pesquisa-ação e etnografia: caminhos cruzados. In: Pesquisas e Práticas sociais, v. 1, n. 1, p. 1, São João del-Rei, jun. 2006.

RESENDE, Viviane de Melo. Literatura de cordel: uma aproximação etnográfica ao gênero. In: Simpósio Internacional de Gêneros Textuais, Anais... Santa Catarina, ago. 2007.

ROJO, Roxane. Letramento e capacidades de leitura para a cidadania. São Paulo: SEE: CENP, 2004.

Alfabetização e letramentos múltiplos: como alfabetizar letrando? In:

RANGEL, E. de O.; ROJO, R. Língua Portuguesa: ensino fundamental. Brasília:

Ministério da Educação, Secretaria de Educação Básica, 2010. (Coleção explorando o ensino; v. 19) 
SANTOS, Lúcia de Fátima. Produção de texto na universidade: em busca de atitudes ativas e táticas. 2007. xxxf. Tese (Doutorado em Linguística), Universidade Federal de Alagoas, Maceió, 2007.

SCHNEUWLY, B; DOLZ, J. Gêneros Orais e Escritos na escola/ tradução e organização Roxane Rojo e Glaís Sales Cordeiro. Campinas, SP: Mercado de Letras, 2010.

SOARES, Magda. Letramento: um tema em três gêneros. 3. ed. Belo Horizonte: Autêntica, 2009.

SOARES, Magda. Letramento e alfabetização: as muitas facetas. Revista Brasileira de Educação. Rio de Janeiro, n. 25, p. 5-17, jan-abr. 2004.

UFAL. Faculdade de Letras. Estabelece normas para a elaboração do Trabalho de Conclusão do Curso de Letras. Resolução n. 2/2009 - FALE, de 17 de setembro de 2009. 


\section{ANEXO}

\section{PELEJA DE UM ALUNO PREGUIÇOSO COM UM ESTUDIOSO}

\section{MANOEL MESSIAS BELIZÁRIO NETO}

Ofereço este cordel

Ao aluno esforçado, Ao aluno preguiçoso, Conversador ou calado Em nome de toda classe De nosso professorado.

Então eu irei narrar

Um duelo interessante

Deu-se em Mata

Redonda Com

dois jovens

estudantes.

Um não estudava nada

Outro estudava

bastante.

Biblioteca ambulante.

\section{CHICO TRIPA}

Melhor ser biblioteca Do que viver sem ser nada, Que nem você que possui A cabeça esvaziada, Ou melhor, cheia de
Chico Tripa era um aluno

Que vivia a estudar Brincava, jogava bola Mas na hora de parar Já ia pegando os livros Pras tarefas aprontar.

Zé de Peba do contrário Era um menino teimoso $\mathrm{Na}$ escrita era péssimo Também lia temeroso Só que o seu problema era Ser um grande preguiçoso.

coisa: Porcaria, bobeirada.

\section{ZE DE PEBA}

Cheleléu de professor, Desses que são bem folgados, Por isso é que você vive Em tudo sendo aprovado. Eu
Zé de Peba tinha raiva Por Chico Tripa viver Lendo livros na escola E gostar de escrever. Certo dia no recreio Resolveu seu saco encher.

\section{ZÉ DE PEBA}

Olha só quem vem aí, Expressou bem radiante,Esse vai é endoidar Lendo livros nas estantes.

Papa-livro, olho de lupa,

como não sou assim Só tiro zero, coitado.

\section{CHICO TRIPA}

Eu passo porque estudo Ninguém vivo a chaleirar, Agora você devia 
Vergonha na cara criar E em suas horas vagas Tirar tempo pra estudar.

\section{ZÉ DE PEBA}

Colega você não venha Me dar lição de moral, Eu não tiro nota boa Não porque eu seja mal, É que em vez de estudar Eu toco meu berimbau.

\section{CHICO TRIPA Tocar}

berimbau meu caro

Não bota uma nota só

No diário, assim

como jogar bola ou

dominó.

Estudar em tempo vago.

Esse é meu borogodó.

\section{ZÉ DE PEBA}

Você é um papa-livros, Isso sim meu camarada.

Perde seu tempo estudando Toda essa besteirada Você quer que eu fique louco Com tanta coisa estudada?

\section{CHICO TRIPA}

Meu amigo estudar Já faz parte do viver. Hoje ou você estuda Ou quando você crescer, Nunca vai ter um emprego Ou talvez o que comer.

\section{ZÉ DE PEBA Não me} venha com conversa, Pois eu conheço pessoas Que nunca pegaram em lápis
E hoje vivem numa boa

E até possuem casas

Nas praias de João

Pessoa.

\section{CHICO TRIPA}

Mas hoje em dia é difícil De esse fato acontecer. Nos tempos de antigamente Não se exigia o saber.

Hoje os meios de trabalho Exigem mais de você.

\section{ZÉ DE PEBA Eu não} penso em trabalhar Pai e mãe quem me sustenta. Por isso vivo a brincar Minha mente não se atenta Com negócio de estudo

Não sei como "tu aguenta."

\section{CHICO TRIPA}

Às vezes tenho preguiça, Mas ela não me domina, Pois penso no meu futuro $E$ é isso que me anima. Um dia serei doutor. Essa será minha sina.

\section{ZE DE PEBA}

Penso em ser advogado, Mas a preguiça é meu forte.

Eu nunca estudo uma prova, Acho que não tenho sorte.

Faz seis anos que estudo E nem sei onde é o norte.
CHICO TRIPA

Você precisa é pensar No futuro de sua vida.

Um dia vai se casar E vai ter que dar comida À sua mulher e filhos E aí qual a saída?

\section{ZÉ DE PEBA}

Você ta é me enrolando Com conversa descabida, Mas acho que tens razão Tenho que pensar na vida. Tirar tempo pra estudar Aí está a saída.

\section{CHICO TRIPA}

Se quiseres captar Um pouco desse aprendiz. Vá amanhã lá em casa A tarefa ainda não fiz. Aí a gente faz junto, $\mathrm{O}$ que você acha? Diz?

\section{ZÉ DE PEBA}

Espera, eu estou pensando: Dou-te a resposta agora. Amanhã bem à tardinha $\mathrm{Eu}$ jogo conversa fora, $\mathrm{E}$ aí depois eu venho $\mathrm{E}$ a gente estuda uma hora.

\section{CHICO TRIPA}

Uma hora é bastante

Para quem quer aprender. Faça como eu estude, Mas estude pra valer E aí as suas notas Vão ser dez, você vai ver. 
Estudantes sempre busquem

Seguir em tom esforçado.

Tarefa bem resolvida

Um prévio bom resultado.

Desejem ver a vitória.

Ajudem o menos dotado.

Nunca excluam um colega

Tenha todos do seu lado

E só assim vocês todos

Serão o nosso legado. 